\title{
Transformation from Local Universities to Application-oriented Universities in China: General Education Reform
}

\author{
Ye ZHANG* \\ Institute of Higher Education \\ Shanghai Polytechnic University \\ Shanghai, China \\ yezhang@sspu.edu.cn
}

\begin{abstract}
After years of research and exploration, a high degree of consensus on the importance and necessity of general education has been reached in higher education fields and much important progress have been made in the theoretical research and practical implementation of general education. With the transformation of local universities to application-oriented universities in China, the university orientation and objective of talents cultivation has changed. Correspondingly, general education of these universities needs to reform. This study analyses the connotation and research background of general education and describes general education curriculum in application-oriented universities in the United States and China. Finally, this puts forward suggestions for the general education reform of China's application-oriented universities. It is also pointed out that general education courses should be reasonably set up, and the teaching methods of general education courses should be enriched, and the students' independent learning ability should be emphasized.
\end{abstract}

Keywords-local universities; application-oriented universities; transformation; general education

\section{INTRODUCTION}

With the popularization of higher education in China, the transformation from local universities to application-oriented universities has become an important national development strategy. In 2014, the state council issued "the decision to accelerate the development of modern vocational education". It proposed to actively guide some local universities to transform to application-oriented universities and emphasized that we should pay more attention to the undergraduate level of application-oriented higher education. In 2015, Premier Li proposed in his government work report that we should "guide some local universities to transform to application-oriented universities”. In 2016, the government work report clearly put forward the "transformation of some local universities to application-oriented universities". Therefore, transformation is imperative. Based on the reform of general education, this paper discusses how to transform the local universities to the application-oriented universities.

This research was financially supported by the Young Research Foundation of the Ministry of Education, the 13th Five-year Plan of National Science of Education (Grant No. EJA170451) in China.

\section{RELATED DEFINITIONS AND LITERATURE REVIEW}

\section{A. Basic Concepts}

General education is a kind of educational thought and practice that has far-reaching influence on the development of modern higher education. It is considered as an effective way to expand the integrated pragmatic competence of university students. It is the core and foundation for the applicationoriented university education. It targets all students of different majors and focuses on non-professional education such as basic knowledge, basic competence, civic awareness and moral quality, personality, aesthetics, and sentiment. General education enables students to gradually realize the history, present and future of China, the relationship between China and the world. It enables students to gradually learn to communicate compromise and cooperate with others, accurately express their opinions, and correctly understand the opinions of others, so that students have the ability to constructively respond to social changes and have good reading and Comprehension ability, thinking and judgment ability, writing and expressing ability, practice and innovation ability. In addition to focusing on knowledge and content itself, general education focuses on the method of acquiring knowledge. Students are allowed to form the features and impressions of application-oriented universities in the fields of international vision, Chinese culture, and practical ability.

Gu Mingyuan defined “General education” as a modern educational thought on the purpose and content of education and education implemented accordingly. In higher education, it refers to education of the common content that all university students should be educated. It is usually divided into several subject areas and provides a wide range of education, which is different from specialized education [1].

The Concept of General education in western countries was first proposed by Aristotle. He advocated "liberal education." He believes that the implementation of "liberal education" is suitable for "value of free people" and can be used to obtain the harmonious development of wisdom, morality, and physicality. He stressed that education should Education should remove utilitarianism and explore profound pure theoretical knowledge. 
General education in universities was first proposed by Prof. AS Parkard of the Bowdion College in the United States in the early 19th century. It refers to the education of students in common subjects at the university level. It belongs to nonprofessional education. It is non-utilitarian. It is adhering to the "complete people" education concept. The Harvard Redbook defines "general education" as "the kind of education that first educates students to be responsible persons and citizens in a democratic society," and believes that the purpose of general education is to cultivate citizens who are responsible and fully developed [2]. Such people have the following four abilities: the ability to think effectively, the ability to communicate ideas clearly, the ability to make appropriate judgments, and the ability to recognize universal values. In a broad sense, general education is carried through the process of reforming university education. Its specific performance is to conduct comprehensive education and training for students. The real purpose of general education is to train students to have a broad perspective and to lay a solid foundation for studying professional knowledge. In a narrow sense, general education is not able to provide students with jobs directly. The purpose of general education is to adapt students to the society better, lay a solid foundation for the healthy development of students' mind and body, and promote students' all-round development from the perspective of nonprofessional education.

\section{B. Literature Review}

The concepts of general education are increasingly prevalent. Research on general education is in full swing. Wang Xiaoyang and Cao Shengsheng, taking general education conducted by Columbia University, University of Chicago, and Harvard University as examples, compared and analysed the characteristics, advantages, and disadvantages of several different general education models, and explore the practical constraints and social and cultural roots of the implementation of general education in the United States. They analyzed the current US strategy for solving general education problems from the following five aspects: integration of general education and professional education, emphasis on extracurricular overseas practice learning, strengthening of curriculum development, promotion of online courses, and emphasis on evaluation of learning outcomes [3]. Liu Xuedong found that in the process of general education reform, Stanford University always upholds the concept of general education, deepens the understanding of the connotation of general education continuously and builds a personalized curriculum system based on different general education philosophies [4]. Zhou Guangli pointed out that general education attaches importance to internal relevance and emphasized that higher education needs to meet students' internal needs and cultivating a person's rational ability is the primary purpose of higher education [5]. Zhang Liang believed that only by starting from the Chinese context and using the principles of localization to construct a set of general education concepts, training objectives, curriculum systems, and institutional norms that are in line with China's actual conditions, can we effectively promote In-depth development of general education in China [6]. Liu Tiefang pointed out that the fundamental significance of general education in universities lies in the fact that it carries the fundamental goal of university education. It means that cultivating complete people with general education instead of generalists [7]. From the perspective of application-oriented universities, Zeng Zhiping, pondered the necessity, implementation status, existing problems and improvement countermeasures for the implementation of general education in application-oriented universities through the analysis of the concept of general education [8].

\section{General EducAtion CuRRiculum in ApPlicAtion- ORIENTED UNIVERSITIES IN THE UNITED STATES AND CHINA}

\section{A. General Education Curriculum in a Community College in the United States}

U.S. Community College courses mainly include three parts: Major Requirements, General Education Requirements, and Free Electives. Major Requirements mainly teach professional knowledge, general education Requirements mainly imparts common sense knowledge, and Free Electives are mainly based on students' personal interests. Take an American Community College as an example, the Community College's general education courses covers eight major categories:

- Humanities and Arts, mainly related to history and art, such as music history, literary history, literary studies, works appreciation, etc.

- Natural science and technology, mainly related to physical science (physics, chemistry), life science (biology, botany, neurology), astronomy and geography, etc.

- Social and behavioral sciences, mainly related to economics, anthropology, sociology, psychology, etc.

- Mathematical logic reasoning, mainly related to mathematics, computer programming, logic, statistics, etc.

- Western cultural studies, mainly related to European and American culture and history.

- Studies on minority cultures and non-western cultures, mainly involves studies on ethnic minorities such as Asia, Africa, Oceania, South America, Indian America, African Americans, etc. and non-mainstream European and American cultures.

- Writing, which mainly teaches the basic outline of academic writing, including the basic points of writing such as how to arguing, citation, collecting evidence, argumentation and conclusion.

- Professional writing, mainly teaching more advanced writing skills, usually combined with various professional courses, to enhance students' ability to search and read literature, summarize and express their opinions in the professional field.

In addition, most Community colleges also require students to learn at least one foreign language, such as French, 
Spanish, German, Chinese, Japanese, Arabic, etc. It can be seen that some disciplines are cross-cutting, for example, cultural studies are often associated with humanities and arts. Another example, "Greek and Roman mythology" can be subordinate to the "Western culture" and "humanities and art" categories.

\section{B. General Education Curriculum in an Application-oriented University in China}

Take an Application-oriented University in China as an example, the general education Curriculum of this university consists of three parts: Ideological and political courses, public basic courses and core courses of general education. Among them, the basic public courses include advanced mathematics, foreign languages, and economics in life.

Core courses of general education enable students to have a wide range of knowledge and a wide field of vision. Students can learn historical and cultural knowledge as well as social knowledge, natural knowledge, scientific knowledge, common sense of life, and artistic accomplishment. In general education, it is necessary to strengthen the learning of basic knowledge and to carry out the study of interdisciplinary courses, cross-curricular courses, and comprehensive courses so as to broaden students' knowledge and broaden their horizons. The core courses of general education are also courses that develop students' minds, develop students' independent thinking skills, and expand students' knowledge. The core courses of general education are designed with three modules: knowledge courses, skills courses, physical and mental health courses. Its guiding principle is to breakthrough pure "professional perspective" and "knowledge perspective" and to provide students with basic humanistic cultivation, vision and spiritual insight, scientific knowledge and basic skills.

Module 1: Knowledge courses - mainly cover subjects such as literature, history, philosophy, politics, natural sciences, engineering technology, economics, law, management, etc. In these courses, students' understanding of literary works and aesthetic tastes are cultivated. These courses enable students to understand things in a historical perspective, enable students to understand the methods of philosophical analysis and cultivate thinking skills, and improve students' appetite, imagination, expressiveness, communication and communication skills. Students are familiarized with some of the major concepts and methods of social sciences to strengthen their understanding of contemporary human behaviour, to correctly understand and handle the problems facing modern society, and to understand the importance of natural sciences and engineering technology to human society. In teaching methods, students should be exposed to the research methods of this discipline through short-term academic explorations through the use of certain pieces of a certain discipline, instead of requiring the students to learn a simplified and relatively complete outline of the discipline or common sense.

The main courses are: Second Foreign Language, General Introduction to China, Introduction to Philosophy, Contemporary World Economy and Politics, Reading and
Writing, Physics, the Charm of Mathematics, Information Technology, Chemical Elements in Life, Procedural Thinking, STEM, dialectics and decision making, introduction to sustainable development, common legal knowledge, introduction to Chinese classical poetry, etc.

Module 2: Skills courses - mainly cover the field of speculative skills and basic technical skills. The teaching content of such courses should be closely linked with social reality and engineering practice to help students improve the formation and application of technological capabilities.

The main courses are: engineering practice and technological innovation, basic engineering skills, career planning, speech and eloquence, innovation and entrepreneurship, negotiation strategies and practices, decision-making and judgment in management, etc.

Module 3: Physical and Mental Health Courses - mainly cover artistic fields such as artistic design and performance, art appreciation and artistic creation. These courses enable students to understand the importance of art and aesthetic experience for the development of human society through the overall understanding of the fields involved. The teaching content of such courses should be closely linked with social and personal life and help students improve their artistic accomplishment and aesthetic awareness. In addition to meeting the general requirements for physical education, sports can carry out distinctive physical education projects such as Tai Chi, shuttlecock and Dragon boat, etc.

The main courses are: Military Theory and Training, Sports, Chinese and Western Music Appreciation, Introduction and Appreciation of Chinese and Western Design Genres, Chinese Painting and Calligraphy Fundamentals, Innovative Thinking and Modern Design, Artistic Design and Expression Techniques, and Chinese Arts Fundamentals, Chinese Martial Arts and Tai Chi, traditional Chinese sports, football and football economic management, basketball and basketball economic management, etc.

\section{Suggestions on General EducAtion Reform in ChinA}

\section{A. Reasonable Setup of General Education Curriculum}

In comparison, the percentage of general education courses in China is relatively low, and the setup of the General education curriculum is also mainly focused on such subjects as ideological and moral cultivation, legal foundations, modern history, philosophy, and foreign languages. For some related courses in natural science, some universities do not include it in general education courses. Given this situation, the general education curriculum in universities in China is obviously in need of readjustment. For example, the proportion of elective courses should be expanded. On the one hand, it can give students more opportunities for free choice and self-study. On the other hand, this also has the function of supplementing and perfecting the general education curriculum, so that the general education curriculum can achieve diversified development. For another example, in the application-oriented universities where science and engineering are dominant, humanities education and professional education are properly combined to allow 
students to clarify the historical background, contemporary development, and career goals of their professional fields.

\section{B. Diverse teaching methods}

As a necessary part of higher education, general education has its traditional side and its contemporary side. Tradition lies in its academic characteristics, which determines that conducting general education is inseparable from the teacher's teaching. The time is in its various forms, this requires teachers to try their best to avoid teaching according to the preaching style when teaching general education courses. Based on the experience of previous generations and the characteristics of students studied, various forms are adopted to allow students to comprehend teaching content and achieve teaching goals.

\section{Cultivation of students' independent learning ability}

We should cultivate students' independence when they receive general education and give students more freedom, especially in reading ability and thinking ability. Whether reading classics or information, students complete the active acquisition of information in an independent time space. At the same time, with the encouragement of thinking and exploring, students are free to generate their own opinions and give their voices to problems or phenomena in the information. Teachers should mobilize students' enthusiasm for learning to the maximum extent and aim to create comprehensive talents that meet the needs of the times.

\section{CONCLUSION}

The purpose of general education is to teach all students basic and comprehensive social common sense. This kind of social common sense is not only in knowledge, but also in the method of dealing with problems. More specifically, it is to help students establish a complete knowledge system and framework to help students form their own values, world views, and better recognize the world and think independently through their own common sense and scientific thinking. The knowledge framework provided by general education is particularly important for modern society. In modern society, the fragmentation of knowledge and information has made many people at a loss. While general education teaches the basic knowledge of each student, it can effectively connect some common knowledge points and form a system to help students receive new knowledge and think independently in their future work and life. In summary, general education is extremely helpful in cultivating independent personality and developing independent thinking skills. Modern Chinese society urgently needs this general education. We often see that liberal arts students do not understand basic physicochemical knowledge, and science students do not understand the basic theories of philosophy of literature and history. Under the background of the transformation of local universities to Application-oriented universities, general education is undoubtedly a feasible and effective method to solve this situation.

\section{ACKNOWLEDGMENT}

The author would like to extend his gratitude to the foundation and Shanghai Polytechnic University. Thanks also go to the anonymous reviewers for their invaluable comments. All the remaining faults are the author's.

\section{REFERENCES}

[1] M. Y. Gu. Education Dictionary. Shanghai: Shanghai Educational Publishing House, 1998. (In Chinese)

[2] R. A. Lanham. A computer-based Harvard red book: general education in the digital age. Gateways to Knowledge: The Role of Academic Libraries in Teaching, Learning and Research. Cambridge, MIT Press, MA, (1997). pp.151-167.

[3] X. Y. Wang, S. S. Cao, "A merican University General Education Models, Challenges and Strategies," China Higher Education Research, 2015, (04), pp.17-25. (In Chinese)

[4] X. D. Liu, "New Vis ion, New Program: Reform of General Education at Stanford University,” Tsinghua Journal of Education, 2014, (05), pp.96102. (In Chinese)

[5] G. L. Zhou, “On the Relevance of Higher Education”, Research in Higher Education of Engineering, 2015, (02), pp.62-69. (In Chinese)

[6] L. Zhang, "General Education Reform in China: Achievements, Dilemma, and Solution,” Tsinghua Journal of Education, 2014, (35:06), pp.80-84, 99. (In Chinese)

[7] T. F. Liu, "The Implication and Practicability of University General Education,” Journal of Higher Education, 2012, (07), pp.1-5.(In Chinese)

[8] Z. P. Zeng, "Exploration and Reflection on the Implementation of General Education in Local Application-oriented Universities,” Reform \& Openning, 2011, (22), pp.180-181. (In Chinese) 